\title{
Do Higher Educated People Feel Better in Everyday Life? Insights From a Day Reconstruction Method Study
}

\author{
Dave Möwisch $^{1,3} \cdot$ Annette Brose $^{2} \cdot$ Florian Schmiedek $^{1}$
}

Accepted: 19 August 2020 / Published online: 1 September 2020

(c) The Author(s) 2020

\begin{abstract}
Past research has shown a positive association between education and well-being. Much of this research has focused on the cognitive component of well-being (i.e., life satisfaction) as outcome. On the other hand, the affective component, that is, how often and intensively people experience positive affect (PA) and negative affect (NA) in their everyday lives, has received far less attention. Therefore, we examined the association between education and PA and NA in everyday life, with a particular focus on affective experiences at the sub-facet level (based on a structure of NA with multiple factors). We used data from a nationally representative sample $(N=1647)$ of the German Socioeconomic Panel Innovation Sample (SOEP-IS), employing the Day Reconstruction Method (DRM) to capture affective experiences of everyday activities. Multilevel structural equation models revealed that (1) education was not related to PA, but (2) was positively associated with two subfacets of NA (mourning/worries and loneliness/boredom); (3) income might in part explain the association between education and NA; (4) education does not particularly seem to serve as a resource in times of unemployment or retirement (i.e., there were no interactions between education and unemployment/retirement regarding well-being) In essence, higher educated people reported fewer negative emotions in everyday life than their lower educated counterparts, but not more positive emotions. The findings underline that different facets of NA, in addition to life satisfaction, are relevant variables related to education and should receive more attention in order to gain a more comprehensive understanding of non-monetary correlates of education.
\end{abstract}

Keywords Education $\cdot$ Affect $\cdot$ Well-being $\cdot$ Day reconstruction method $\cdot$ SOEP-innovation sample

This research was funded by the grant NimoErt1 from the Federal Ministry of Education and Research (BMBF). We thank Oliver Huxhold for helpful advice.

Electronic supplementary material The online version of this article (https://doi.org/10.1007/s1120 5-020-02472-y) contains supplementary material, which is available to authorized users.

Dave Möwisch

dave.moewisch@lifbi.de

Extended author information available on the last page of the article 


\section{Introduction}

The field of research on subjective well-being (SWB) is one of the fastest growing areas in social and life sciences (Diener and Scollon 2014), with many publications on antecedents and consequences of feeling well. SWB is associated with several positive outcomes such as health, social relationships, and resilience (Diener et al. 1999; Kansky and Diener 2017). Furthermore, there is growing interest in how to promote SWB at the individual and national levels (Kahneman et al. 2004a). For example, economists are interested in how socio-economic variables such as education can foster higher levels of SWB (Dolan et al. 2008). In this context, it has been postulated that the returns of education have a positive effect on the possibility to satisfy human needs through better material and non-material living conditions (Vila 2001). In this regard, the outcomes of education can be viewed as human capital that likely impacts individual lives way beyond economic productivity (Becker 1993). Thus, SWB can be considered as a non-monetary outcome of education.

The majority of studies on the relationship between education and SWB have found a positive association between education and SWB (e.g., Diener et al. 1999; Witter et al. 1984). Better educated people seem to be happier and more satisfied with their own life than their less educated counterparts. However, there are three issues that have not been considered sufficiently in the literature so far.

First, studies often use life satisfaction as the only indicator of SWB. According to Diener (1984), however, SWB consists of two different components: the cognitive and the affective component. The cognitive component is defined by global judgements of one's life and satisfaction with different life domains (e.g., work satisfaction). The affective component is characterized by the experience of positive affect (PA) and negative affect (NA). To date, there has been only a limited number of studies examining the association between the affective component of well-being and education. That is, there is a lack of information about whether more highly educated individuals are not only more satisfied with their life but also feel better in everyday life than less highly educated individuals. This is of particular interest since specifically affective well-being is linked to a number of health-related outcomes such as a lower risk of mortality (Moskowitz et al. 2008) or fewer symptoms of illness (Pettit et al. 2001).

Second, researchers commonly use composite scores based on retrospective self-reports of PA and NA as indicators of well-being. However, such composite scores of retrospective self-reports pose two problems. On the one hand, retrospective reports are commonly biased by memory effects and beliefs about the self (Robinson and Clore 2002). Scholars thus suggest aggregated scores across repeated assessments (e.g., mean levels across the occasions of a diary study) per person as an alternative to retrospective reports. Such scores were shown to have distinct predictive validity on numerous outcome variables (Conner and Barrett 2012), indicating that they are more relevant than retrospective reports. On the other hand, composite scores are commonly computed across different sub-facets of affect, neglecting the multidimensional structure of affect. However, there are alternatives to such composite scores, mainly because there are instances in which a multidimensional conceptualization of affect seems superior to differentiating between only two global dimensions (e.g., Möwisch et al. 2019).

Third, little is known about variables that possibly affect the relationship between education and SWB (Chen 2012; Desjardins 2008). The OECD (2007) concluded that there is a lack of coherent information about possible mechanisms linking education and SWB. However, some potentially relevant variables have been studied, such as income (e.g., 
Dolan et al. 2008) or unemployment (McKee-Ryan et al. 2005). In these studies, researchers focused predominantly on mechanisms between education and life satisfaction. Therefore, there is little evidence on variables that possibly affect the relationship between education and PA/NA. ${ }^{1}$

The purpose of the present study was to address the following three issues. First, we intended to investigate the relationship between education and the affective component of well-being (Aim 1). We then wanted to conceptualize affective well-being in a more nuanced way than other studies in this field of research, and to examine the association between education and phenomenologically distinguishable facets of affect (Aim 2; cf. Möwisch et al. 2019). Third, we set out to examine the extent to which income, employment status, and retirement influence the relationship between education and affective wellbeing (Aim 3).

\subsection{Education and Subjective Well-being}

Research across various disciplines, including economics, sociology, and psychology, has shown a positive association between education and the cognitive component of SWB (e.g., Blanchflower and Oswald 2004, 2005; Powdthavee et al. 2015). In their meta-analysis, Witter et al. (1984) concluded that there is a weak positive association between formal education and SWB; the latter was mostly measured as life satisfaction or domain-specific satisfaction (e.g., work satisfaction). More recently, a study with four different national surveys also revealed a positive association between education and happiness with one's own life (Easterbrook et al. 2016). Non-significant or negative associations between life satisfaction and education have been reported comparatively rarely (e.g., Anand et al. 2005; Clark and Oswald 1996; Headey 2008).

In comparison, fewer studies have examined the relationship between education and the affective component of SWB (PA and NA). Based on an analysis of two nationally representative data sets of US households, Ross and Van Willigen (1997) pointed out that higher educated persons are less depressed, anxious, and angry than lower educated persons. In a study investigating the validity of the PANAS scales, Crawford and Henry (2004) found a significant positive correlation between education and PA and a non-significant correlation with NA. A positive direct effect of education on happiness (as an aspect of PA) was also found in a Spanish sample, even after controlling for socio-economic variables such as income (Cuñado and de Gracia 2012). In a recent study by Nikolaev (2018), education was associated with more positive and fewer negative emotions. Similarly, another recent study using data from the European Social Survey revealed a positive effect of vocational and tertiary education on emotional well-being, including on PA (Jongbloed 2018). ${ }^{2}$

However, there are also studies that have found no significant or even contrary associations. For example, Collins, Sarkisian, and Winner (2009) found a positive association

\footnotetext{
1 The results remain unchanged after controlling for the death of a family member in the last year. As a reviewer noted, such an event could affect the association between education and especially NA3 (mourning and worries). The results also remain robust after controlling for self-reported health.

2 To compare and interpret the regression coefficients between education and PA/NA, the measurement models of PA and NA in both groups have to be tested for measurement invariance (Brown 2014). Our results indicated partial metric measurement invariance across both groups for the measurement models of PA and NA (i.e., only the factor loadings for NA1 were allowed to vary in both groups). Therefore, the regression coefficients between education and PA/NA were comparable in both groups
} 
between education and NA. In their study, higher educated persons were more nervous, afraid, and aroused than lower educated persons. Moreover, the World Happiness Report did not show any associations between education and PA and NA (Helliwell et al. 2012). Together, the majority of these studies indicate a positive association between education and affective well-being, but the empirical basis is still inconclusive.

Importantly, these studies used either global composite scores or single items (e.g., happiness) to measure NA und PA, which is a common approach for capturing affective well-being. However, these composite scores can lead to a loss of information (Schimmack 1999). For example, Watson and Tellegen (1985) distinguished between two broad global dimensions of affect: positive and negative. According to their conceptualization, these dimensions represent higher-order factors that embrace several discrete emotions at lower levels, based on the assumption that affect has a hierarchical structure (Tellegen et al. 1999). Moreover, appraisal theorists (e.g., Lazarus 1991; Scherer 2001) have postulated that affective states are characterized by phenomenologically distinguishable facets as a result of appraisal processes, supporting the idea of a more nuanced structure of affect. Thus, we differentiated between multiple sub-facets of NA to address the problem of global composite scores and to gain information about the relationship between education and affect at the level of sub-facets. Specifically, instead of investigating a global composite score, we distinguished between the factors NA1 (anger/frustration/ stress), NA2 (mourning/worries), and NA3 (loneliness/boredom). NA1 (anger, frustration, stress) is characterized by a high level of arousal. The other sub-facets (NA2 (mourning, worries) and NA3 (boredom, loneliness)) represent moderate to low levels of arousal and reflect specific feelings that are high in valence. Moreover, NA3 (boredom, loneliness) can be described as a lack of stimulation. Boredom generally reflects a lack of internal and external stimulation (Struk et al. 2016), while loneliness represents a lack of social stimulation. Based on the literature, we expected a positive association between educational attainment and PA and a negative association with all three subfacets of NA.

Furthermore, previous studies used retrospective self-reports of PA and NA referring to a longer period of time, such as "in the last year," to examine the association between education and affective well-being. Alternatively, individual differences in PA and NA can be obtained by measuring affect repeatedly and in close proximity to when the affect is experienced, which is the approach of the Day Reconstruction Method (DRM; Kahneman et al. 2004b). The DRM captures information about activities in everyday life and related affective experiences by reconstructing the previous day. This method allows the study of variation in PA and NA within persons across situations. Importantly, it also allows the investigation of variation between persons when information across situations is aggregated per person. This approach provides a different type of information on between-person differences in affective experiences than the more common retrospective self-reports. The latter are based on episodic and semantic knowledge, while online ratings measure actually felt affective experiences (Robinson and Clore 2002). Importantly, the different sources of information used for current versus non-current emotion reports can lead to discrepancies between the two types of report. The validity of the distinction has more recently been supported empirically by a study which found retrospective and mean levels of current emotion reports to be distinguishable predictors of outcomes (Conner and Barrett 2012). Therefore, we shifted our measurement approach to the use of repeated momentary assessments of affect during daily activities using the DRM. 


\subsection{The Role of Income, Unemployment, and Retirement in the Education-Well-being Association}

Several factors can influence the level of SWB (Diener et al. 1999). For example, the following mechanisms are supposed to mediate the association between education and affective well-being: better health behavior (Ross and Wu 1995), higher optimism, higher levels of self-esteem, more control over one's own life (Cummins 2000) as well as better functioning social networks of higher educated persons (Chen 2012).

In this study, we focus on income, unemployment, and retirement (e.g., Dolan et al. 2008; Luhmann et al. 2012) because we expect monetary effects of education on wellbeing, which operate via income, and non-monetary effects of education on well-being which should be revealed by the interaction of education and unemployment / retirement in the prediction of well-being. In the following, we will elaborate on potential moderating and mediating relationships between these variables.

\subsubsection{Income}

Income has been identified as an important mechanism linking education and SWB (see Clark et al. 2008, for an overview) - it may in fact be one of the main channels through which education could have a positive impact on SWB (Dolan et al. 2008). Bivariate studies provide evidence of positive associations between education and income (Aryee et al. 1999; Vila, 2005) as well as between income and SWB (Gardner and Oswald 2007; Howell and Howell 2008). Over and above this, one study showed that education is positively associated to SWB through income (Powdthavee et al. 2015). However, these studies examined the relationship between education, income, and life satisfaction, but not between education, PA and NA. Moreover, correlations between income and the different components of SWB (life satisfaction vs. PA/NA) can vary (Luhmann et al. 2011). Therefore, we considered income as a potentially linking variable between education and PA and NA. Specifically, higher income generated by higher education should be associated with fewer worries in everyday life (cf. Payne and Hartley 1987). Furthermore, a higher income is likely to enable more opportunities to visit friends or pursue specific leisure time activities which can lead to less loneliness and boredom in everyday life.

Additionally, income might moderate the association between education and SWB. Income could serve as a resource and mitigate the potentially negative effect of low levels of education on well-being. For example, Rief et al. (2012) showed that less educated individuals were more worried about their health than higher educated people in a German sample. A higher income could buffer this negative association between education and health because more financial resources allow for better health care and possibly reduce health-related worries. Therefore, we investigated the interaction of education and income regarding PA and NA.

\subsubsection{Unemployment and Retirement}

In addition to the monetary effect of education and well-being via income, we expected non-monetary effects of education to impact well-being. These effects can be revealed by considering other aspects of one's current economic living conditions. We focused on unemployment and retirement for two reasons. Both variables are related to well-being 
(Luhmann et al. 2012), and education could be viewed as human capital that may be particularly relevant for well-being during unemployment and retirement. Thus, we assume an interaction between education and unemployment/retirement in the prediction of wellbeing in the following.

Unemployment. The possible effect of education on well-being might depend on how strongly it is needed as a resource. Education is considered to be one of the most important aspects of human capital (Becker 1993); the latter can be understood as the accumulation of knowledge, skills, and abilities. In the life-facet model of coping, McKee-Ryan and Kinicki (2002) elaborated on the role of human capital more generally and in particular in situations when people face unemployment. Aspects of human capital can be a beneficial resource during unemployment and thus have a buffering effect on a potential decline in well-being during unemployment. For example, McKee-Ryan et al. (2005) reported in their meta-analysis that higher educated people have better mental health and higher life satisfaction during unemployment. Thus, more highly educated persons seem to succeed better in maintaining their well-being during episodes of unemployment than their less educated counterparts. For example, existential worries in everyday life might be buffered by higher education, since higher educated individuals may be more optimistic and have better chances of reemployment. Given that this meta-analysis focused on life satisfaction, we will examine the potential buffering effect of education on PA and NA during unemployment.

Retirement. Similar to unemployment, retirement can have a negative effect on wellbeing, for example, through the loss of social contacts to co-workers (Kim and Moen 2002). Education could also be an important resource during this phase of life. Higher educated people have stronger social networks (Nieminen et al. 2008; Pichler and Wallace 2009) and tend to be more socially active after retirement (Wetzel and Huxhold 2016). Social contacts are particularly important after retirement, because social structure often changes in the absence of work, which has potential effects on well-being. For example, Crisp, Windsor, Butterworth, and Anstey (2015) showed that larger social networks lead to lower levels of loneliness after retirement. Thus, we investigated education as a potential resource during retirement in terms of affective well-being.

\section{Method}

\subsection{Participants and Procedure}

This study used data from the SOEP-IS (Richter and Schupp 2015), which constitutes a nationally representative sample of the German population. To collect the data, German households were visited. Interviews were conducted with all household members who had reached at least the age of 16. The data were collected in Computer-Assisted Personal Interviews (CAPI) conducted by trained interviewers. For the data analysis, we used two consecutive waves of the SOEP-IS (2012 and 2013). As part of the DRM, participants were first asked when they had woken up on the previous day. Subsequently, they were asked to describe what they had done next by referring to a list of 24 possible activities such as "work." This procedure was repeated until the entire day had been reconstructed for one day per wave. Additional information collected on the episodes (e.g., starting and ending times of the episodes, interaction partners) will not be considered in this study. On average, the participants reported 11.1 episodes per day $(S D=4.1)$. All participants provided their 
informed consent; the Institutional Review Board of the German Institute for Economic Research approved the study.

The mean age of the participants was 56.02 years ( $\mathrm{SD}=15.09$, range: $28-96)$. All participants under the age of 28 were excluded from the initial sample because they had not (yet) reached the opportunity to achieve the highest level of education. We chose 28 as a cut-off value because the mean age at first university graduation was 28 years in our sample. Fifty-seven percent of all participants were female $(57.5 \%)$, and $37 \%$ were retirees $(37.3 \%)$. Seventy-five percent of the employed individuals were in full-time employment or regular part-time employment (75.6\%). The total sample included 1647 participants.

\subsection{Measures}

\subsubsection{Affective Well-being}

The study participants provided information on how they felt during three episodes that they had reported in the DRM. The three episodes were selected randomly by the CAPI program. We used the following items for the analyses: happiness, enthusiasm, satisfaction, anger, frustration, stress, mourning, worries, boredom, and loneliness. The answering scale ranged from 1 (not at all) to 7 (very much). The selection of items was based on previous research (Anusic et al. 2017; Möwisch et al. 2019).

\subsubsection{Educational Attainment}

Individual educational attainment was measured using the international standard classification of education developed by the UNESCO to internationally compare educational systems and educational attainment levels (ISCED-97; Unesco, 1997). The ISCED comprises six different levels (including the percentage distributions in the total sample): Level $1=$ primary education $(1.2 \%)$, Level $2=$ lower secondary education $(11.2 \%)$, Level $3=$ upper secondary education $(53.8 \%)$, Level $4=$ post-secondary non-tertiary education $(6.0 \%)$, Level $5=$ first stage of tertiary education $(5.8 \%)$, Level $6=$ second stage of tertiary education (22\%). In order to improve the distribution of the education variable, we merged Levels 1 and 2 into "low education level," Levels 3 and 4 into "moderate education level," and Levels 5 and 6 into "high education level." We computed three dummy-coded variables to compare the three levels with each other ("low vs. moderate," "moderate vs. high," and "low vs. high").

\subsubsection{Income, Unemployment, and Retirement}

The current gross labor income and current gross secondary income (additional sources of income) of each participant served as indicators for income. The employment status was covered by a dummy-coded variable comparing "unemployment" and "employment." Retirement was assessed with a binary variable and could be answered with "yes" or "no."

\subsection{Statistical Analyses}

To test Aim 1 and Aim 2 (to examine the relationship between educational attainment and PA/NA), we conducted regression analyses via multilevel structural equation 


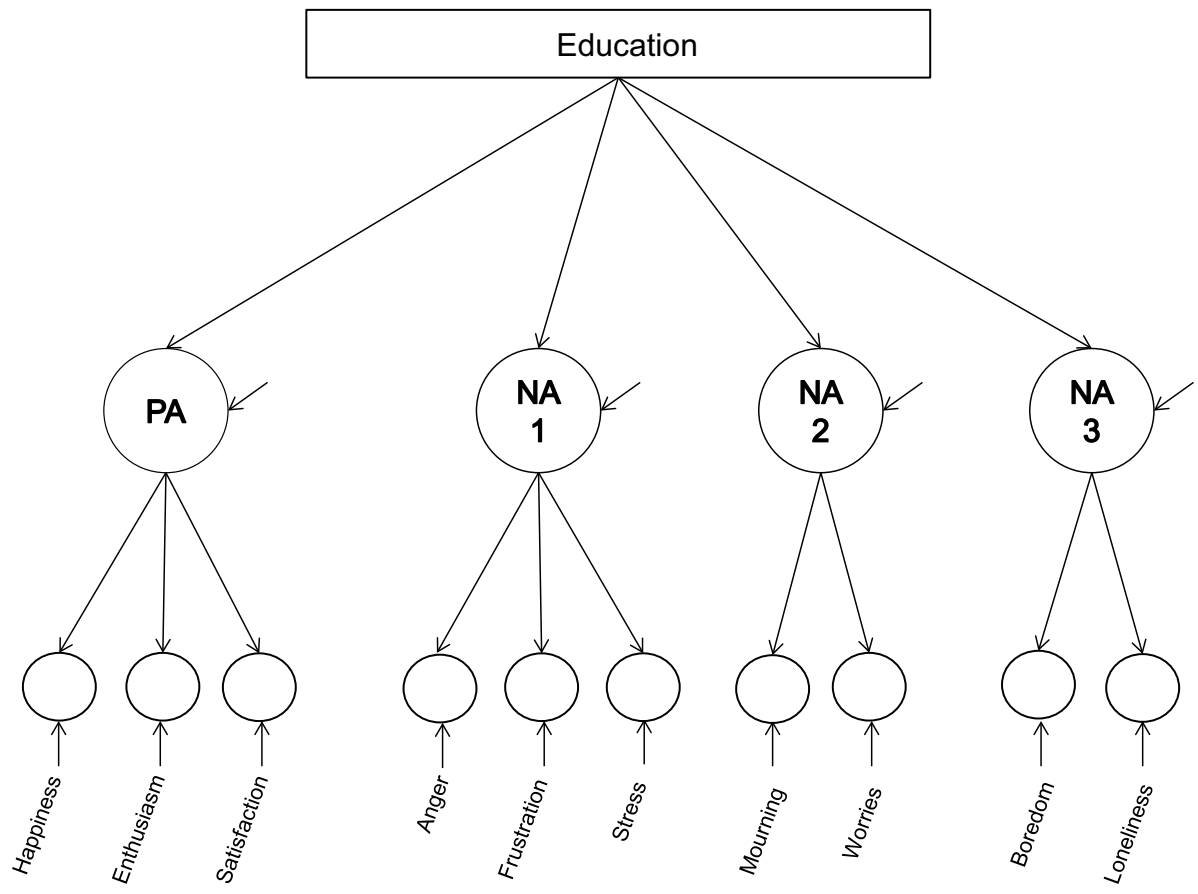

Fig. 1 Measurement model of positive affect (PA) and negative affect (NA) and the regression path on education at the between-person level

modeling using Mplus 7.4 (Muthén and Muthén 1998-2015). This multilevel approach (with repeated affect ratings nested within persons) allows the examination of models and associations of variables between persons as well as within persons across situations. One important aspect of the model was the representation of the factor structure of PA and NA on two levels, at the within-person and at the between-person level. This was accomplished by separating the within- and between-person variance of PA and NA and by modeling factor structures at both levels. The factor structure at the between-person level reflected the structure of items' mean levels across different situations. The emerging latent variables at the between-person level were used to examine the association between education and affective well-being.

In accordance with the theory and statistical analyses reported in Möwisch et al. (2019), we modeled one PA factor and three NA factors, all of which were supposed to be related. More precisely, a comparison of models using the same data as in this study reported in Möwisch et al. (2019) revealed that this model fitted better than other measurements models (e.g., a model with only one factor for NA).

In the multilevel structural equation model, we regressed the latent affect factors (one PA factor and three NA factors) at the between-person level on education (see Fig. 1) to examine the relationship between education and affective well-being. We used the three dummy-coded variables "low vs. moderate," "moderate versus high," and "low vs. high" to compare the influence of different levels of education on PA/NA.

To address Aim 3 (to examine how income, unemployment, and retirement affect the relationship between education and PA/NA), we first included income in the regression 
analyses. We then used path analyses to investigate possible indirect effects of education via income on PA and NA. To investigate the interaction between education and employment status and retirement, respectively, in the prediction of well-being, we conducted multigroup analyses (employed vs. unemployed, retired vs. not retired). Here, we investigated whether the regression coefficients between education and PA/NA differed in the two groups of employed and unemployed people as well as in the two groups of retired and non-retired people. To test whether differences in regression coefficients were significant, we performed the Satorra-Bentler scaled $\chi^{2}$-difference test (Satorra and Bentler 2001).

The models were estimated according to the principle of robust maximum-likelihood (MLR), which uses parameter estimates with standard errors and chi-square statistics which are robust to non-normality and non-independence of observations. The missing data were managed with a full-information maximum likelihood approach (FIML). We evaluated the model fit using the comparative fit index (CFI), root mean square error of approximation (RMSEA), and the standardized root mean square residual (SRMR). We applied the conventional cut-off criteria proposed by Hu and Bentler (1999), that is, 0.95 or higher for CFI, 0.08 or lower for SRMR, and 0.06 or lower for RMSEA.

\section{Results}

\subsection{Educational Attainment and Affective Well-being}

To address Aims 1 and 2 (to examine the relationship between educational attainment and PA and NA), PA and NA were regressed on education in three separate models (Model 1: comparison of low vs. high education; Model 2: comparison of low vs. moderate education; Model 3: comparison of moderate vs. high education). Age and gender were included as control variables in the models. The model fit indices indicated an acceptable model fit for all three models. Table 1 presents the regression coefficients and model fit indices for Models 1-3. In Model 1 (low vs. high education), education was significantly negatively related to NA2 (mourning, worries) and NA3 (boredom, loneliness). Accordingly, people with a higher level of education felt less sad and worried as well as less lonely and bored in everyday life than people with a low level of education. In Model 2 (low vs. moderate education), education was also negatively associated with NA2 (mourning, worries) and NA3 (boredom, loneliness). Moderately educated people reported less mourning and worries (NA2) and less loneliness and boredom (NA3) in everyday life than people with low levels of education. In contrast, Model 3 (moderate vs. high education) revealed no significant associations between education and the facets of PA and NA. To sum up, education did not predict PA in Models 1 to 3. Yet, higher education was associated with less NA except for in the model comparing moderate vs. high education, where there were no significant effects of education. ${ }^{1}$

\subsection{The Role of Income, Unemployment, and Retirement}

Bivariate correlations between the variables income, unemployment, and retirement as well as education and well-being are reported in the Supplement. The directions of the correlations generally correspond to our expectations: Income was positively related to education and negatively related to NA2 (mourning, worries) and NA3 (loneliness, boredom); employment status (unemployed vs. employed) was negatively related to NA2 (mourning, 
Table 1 Standardized regression coefficients for educational attainment and PA/NA

\begin{tabular}{|c|c|c|c|c|}
\hline $\begin{array}{l}\text { Affect factors-between- } \\
\text { level- }\end{array}$ & PA & $\begin{array}{l}\text { NA1 (Anger, } \\
\text { Frustration, } \\
\text { Stress) }\end{array}$ & $\begin{array}{l}\text { NA2 (Mourning, Wor- } \\
\text { ries) }\end{array}$ & $\begin{array}{l}\text { NA3 (Loneli- } \\
\text { ness, Boredom) }\end{array}$ \\
\hline \multicolumn{5}{|l|}{ Model $1^{\mathrm{a}}$} \\
\hline ISCED (low vs. high) & $-0.033(0.05)$ & $-0.061(0.05)$ & $-0.175(0.05)^{*}$ & $-0.214(0.05)^{*}$ \\
\hline Gender & $-0.008(0.05)$ & $.099(0.05)$ & $0.076(0.05)$ & $0.035(0.05)$ \\
\hline Age & $0.015(0.05)$ & $-0.344(0.05)^{*}$ & $-0.049(0.06)$ & $0.037(0.05)$ \\
\hline \multicolumn{5}{|l|}{ Model $2^{b}$} \\
\hline $\begin{array}{l}\text { ISCED (low vs. moder- } \\
\text { ate) }\end{array}$ & $-0.061(0.04)$ & $-0.094(0.04)$ & $-0.137(0.04)^{*}$ & $-0.154(0.04)^{*}$ \\
\hline Gender & $-0.005(0.04)$ & $-0.031(0.04)$ & $0.013(0.03)$ & $-0.067(0.04)$ \\
\hline Age & $-0.097(0.04)^{*}$ & $-0.263(0.04)^{*}$ & $-0.017(0.04)$ & $0.048(0.03)$ \\
\hline \multicolumn{5}{|l|}{ Model $3^{c}$} \\
\hline $\begin{array}{l}\text { ISCED (moderate vs. } \\
\text { high) }\end{array}$ & $-0.006(0.03)$ & $0.044(0.03)$ & $-0.019(0.03)$ & $-0.045(0.03)$ \\
\hline Gender & $-0.004(0.03)$ & $-0.007(0.03)$ & $.004(0.03)$ & $-0.064(0.03)$ \\
\hline Age & $-0.066(0.03)$ & $-0.284(0.03)^{*}$ & $-0.014(0.03)$ & $0.025(0.04)$ \\
\hline
\end{tabular}

${ }^{\mathrm{a}} k=678, \quad n=3289$, Model fit indices: $\mathrm{CFI}=0.953$, SRMR-within $=0.038, \quad$ SRMR-between $=0.059$, RMSEA $=0.035$

b $\mathrm{k}=1167, n=5676$, Model fit indices: CFI $=0.965$, SRMR-within $=0.034$, SRMR-between $=0.049$, RMSEA $=0.029$

c $\mathrm{k}=1449, n=7069$, Model fit indices: $\mathrm{CFI}=0.956$, SRMR-within $=0.034$, SRMR-between $=0.052$, $\mathrm{RMSEA}=0.033$

Standard errors are shown in brackets. ${ }^{*} p<0.01$. Gender: $0=$ male, $1=$ female

worries) and NA3 (boredom, loneliness); retirement (non-retired vs. retired) was positively related to NA2 (mourning, worries) and NA3 (boredom, loneliness).

\subsubsection{Income}

To examine the effect of income on the relationship between education and PA/NA (Aim 3 ), we first included income in a further set of three regression models. The results of these analyses are presented in Table 2. The model fit indices were acceptable for these models. In Model 1 (low vs. high education), there were no significant associations between income and the latent affect factors. More importantly, the regression coefficients between education and PA/NA did not change after we included income. The significant negative coefficients between education and NA (NA2 and NA3) remained significant after income was included. Path analyses revealed no significant indirect effects of education on NA via income for Model 1 and Model 2 (Model 1: NA2: $\mathrm{B}=-0.001 ; S E=0.01 ; p>0.01$; NA3: $\mathrm{B}=0.002 ; S E=0.01 ; p>0.01 ;$ Model 2 : NA2: $\mathrm{B}=-0.010 ; S E=0.01 ; p>0.01 ; \mathrm{NA} 3$ : $\mathrm{B}=-0.012 ; S E=0.01 ; p>0.01$ ). In Model 3 (moderate vs. high education), there were no significant effects of income and education on NA2 (mourning, worries) and NA3 (boredom, loneliness).

To examine whether income moderates the association between education and SWB, we investigated the interaction of education and personal income in the prediction of PA and NA (see Table 3). The results revealed significant interaction effects for NA2 (mourning, 
Table 2 Standardized regression coefficients for educational attainment, PA/NA, and income

\begin{tabular}{|c|c|c|c|c|}
\hline $\begin{array}{l}\text { Affect factors-between- } \\
\text { level- }\end{array}$ & PA & $\begin{array}{l}\text { NA1 (Anger, } \\
\text { Frustration, } \\
\text { Stress) }\end{array}$ & $\begin{array}{l}\text { NA2 (Mourning, Wor- } \\
\text { ries) }\end{array}$ & $\begin{array}{l}\text { NA3 (Loneli- } \\
\text { ness, Boredom) }\end{array}$ \\
\hline \multicolumn{5}{|l|}{ Model $1^{\mathrm{a}}$} \\
\hline ISCED (low vs. high) & $-0.044(0.05)$ & $-0.073(0.05)$ & $-0.176(0.05)^{*}$ & $-0.212(0.05)^{*}$ \\
\hline Gender & $0.004(0.04)$ & $0.113(0.05)$ & $0.077(0.05)$ & $0.033(0.04)$ \\
\hline Age & $0.033(0.05)$ & $-0.327(0.06)^{*}$ & $-0.048(0.06)$ & $0.035(0.05)$ \\
\hline Income & $0.059(0.06)$ & $0.062(0.05)$ & $0.003(0.05)$ & $-0.007(0.04)$ \\
\hline \multicolumn{5}{|l|}{ Model $2^{b}$} \\
\hline $\begin{array}{l}\text { ISCED (low vs. moder- } \\
\text { ate) }\end{array}$ & $-0.056(0.04)$ & $-0.094(0.04)$ & $-0.132(0.04)^{*}$ & $-0.148(0.04)^{*}$ \\
\hline Gender & $-0.017(0.04)$ & $-0.029(0.04)$ & $0.000(0.04)$ & $-0.082(0.04)$ \\
\hline Age & $-0.123(0.04)^{*}$ & $-0.259(0.04)^{*}$ & $-0.046(0.04)$ & $0.014(0.04)$ \\
\hline Income & $-0.060(0.04)$ & $.008(0.05)$ & $-0.064(0.04)$ & $-0.076(0.03)$ \\
\hline \multicolumn{5}{|l|}{ Model $3^{c}$} \\
\hline $\begin{array}{l}\text { ISCED (moderate vs. } \\
\text { high) }\end{array}$ & $0.004(0.03)$ & $0.032(0.03)$ & $0.016(0.03)$ & $-0.032(0.03)$ \\
\hline Gender & $-0.003(0.03)$ & $0.003(0.04)$ & $0.002(0.03)$ & $-0.075(0.03)$ \\
\hline Age & $-0.063(0.04)$ & $-0.267(0.04)^{*}$ & $-0.018(0.04)$ & $0.005(0.04)$ \\
\hline Income & $0.009(0.04)$ & $0.048(0.04)$ & $-0.012(0.04)$ & $-0.055(0.03)$ \\
\hline
\end{tabular}

${ }^{\mathrm{a}} k=678, \quad n=3289$, Model fit indices: $\mathrm{CFI}=0.954, \quad \mathrm{SRMR}$-within $=0.038, \quad$ SRMR-between $=0.056$, RMSEA $=0.034$

b $k=1167, n=5676$, Model fit indices: CFI=0.966, SRMR-within $=0.034$, SRMR-between $=0047$, RMSEA $=0.028$

c $k=1449, n=7069$, Model fit indices: CFI $=0.957$, SRMR-within $=0.034$, SRMR-between $=0.050$, RMSEA $=0.032$

Standard errors are shown in brackets. ${ }^{*} p<0.01$. Gender: $0=$ male, $1=$ female

worries) in Model 1 (low vs. high education) and Model 2 (low vs. moderate education). The interaction effects are shown in Figs. 2 and 3. These indicate that individual educational background only seems to be a relevant covariate for NA2 (mourning, worries) for lower levels of personal income. For higher levels of personal income, the differences in NA2 (mourning, worries) decrease between the lower educated and highly educated persons. However, this interaction effect did not appear for the other sub-facets of NA.

In addition to the interaction effects, we also sought to identify indirect effects between education and NA via income in this model. In Model 1 (low vs. high education) and Model 2 (low vs. moderate education), there were also indirect effects of education on NA2 (mourning, worries) via income (Model 1: $\mathrm{B}=-0.151 ; S E=0.04 ; p<0.01$; Model 2: $\mathrm{B}=-0.046 ; S E=0.01 ; p<0.01)$. Thus, the significant association between education and NA2 (mourning, worries) can be partly explained by the higher incomes of higher educated persons. Nevertheless, the direct effect of education on NA2 (mourning, worries) remained significant. In sum, there are indirect and moderating effects of income on the association between education and NA2 (mourning, worries). 
Table 3 Standardized regression coefficients for educational attainment, PA/NA, income, and interactions

\begin{tabular}{|c|c|c|c|c|}
\hline $\begin{array}{l}\text { Affect factors-between- } \\
\text { level- }\end{array}$ & PA & $\begin{array}{l}\text { NA1 (Anger, } \\
\text { Frustration, } \\
\text { Stress) }\end{array}$ & $\begin{array}{l}\text { NA2 (Mourning, Wor- } \\
\text { ries) }\end{array}$ & $\begin{array}{l}\text { NA3 (Loneli- } \\
\text { ness, Boredom) }\end{array}$ \\
\hline \multicolumn{5}{|l|}{ Model $1^{\mathrm{a}}$} \\
\hline ISCED (low vs. high) & $-0.061(0.06)$ & $-0.085(0.06)$ & $-0.228(0.06)^{*}$ & $-0.221(0.05)^{*}$ \\
\hline Gender & $0.000(0.05)$ & $0.109(0.05)$ & $0.063(0.05)$ & $0.030(0.05)$ \\
\hline Age & $0.024(0.06)$ & $-0.333(0.06)^{*}$ & $-0.076(0.06)$ & $0.029(0.05)$ \\
\hline Income & $-0.133(0.25)$ & $-0.093(.28)$ & $-0.621(0.18)^{*}$ & $-0.167(0.24)$ \\
\hline ISCED x Income & $0.199(0.26)$ & $0.161(0.28)$ & $0.653(0.18)^{*}$ & $0.168(0.25)$ \\
\hline \multicolumn{5}{|l|}{ Model $2^{b}$} \\
\hline $\begin{array}{l}\text { ISCED (low vs. moder- } \\
\text { ate) }\end{array}$ & $-0.073(0.04)$ & $-0.101(0.04)$ & $-0.169(0.05)^{*}$ & $-0.158(0.05)^{*}$ \\
\hline Gender & $-0.018(0.04)$ & $-0.029(0.04)$ & $-0.002(0.04)$ & $-0.083(0.04)$ \\
\hline Age & $-0.126(0.04)^{*}$ & $-0.260(0.04)^{*}$ & $-0.052(0.04)$ & $0.013(0.04)$ \\
\hline Income & $-0.188(0.12)$ & $-0.054(0.14)$ & $-0.347(0.08)^{*}$ & $-0.155(0.12)$ \\
\hline ISCED x Income & $0.142(0.12)$ & $0.067(0.14)$ & $0.310(0.09)^{*}$ & $0.090(0.12)$ \\
\hline \multicolumn{5}{|l|}{ Model $3^{c}$} \\
\hline $\begin{array}{l}\text { ISCED (moderate vs. } \\
\text { high) }\end{array}$ & $-0.011(0.04)$ & $0.029(0.06)$ & $-0.033(0.04)$ & $-0.068(0.04)$ \\
\hline Gender & $-0.005(0.04)$ & $0.002(0.04)$ & $-0.002(0.03)$ & $-0.081(0.04)$ \\
\hline Age & $-0.069(0.03)$ & $-0.270(0.04)^{*}$ & $-0.025(0.04)$ & $-0.009(0.04)$ \\
\hline Income & $-0.026(0.06)$ & $0.038(0.04)$ & $-0.050(0.06)$ & $-0.133(0.06)$ \\
\hline ISCED x Income & $0.047(0.07)$ & $0.011(0.07)$ & $0.052(0.06)$ & $0.108(0.06)$ \\
\hline
\end{tabular}

${ }^{\mathrm{a}} k=678, \quad n=3289$, Model fit indices: $\mathrm{CFI}=0.949, \quad \mathrm{SRMR}-$ within $=0.038, \quad$ SRMR-between $=0.078$, RMSEA $=0.038$

b $\mathrm{k}=1167, n=5676$, Model fit indices: $\mathrm{CFI}=0.950$, SRMR-within $=0.034$, SRMR-between $=0.082$, RMSEA $=0.034$

c $k=1449, n=7069$, Model fit indices: CFI =0.957, SRMR-within $=0.034$, SRMR-between $=0.058$, RMSEA $=0.033$

Standard errors are shown in brackets. $* x<0.01$. Gender: $0=$ male, $1=$ female

\subsubsection{Employment Status}

To investigate a potential interaction between education and employment status regarding affective well-being, we used multigroup modeling and excluded all retirees from the analysis. In particular, we examined whether the regression coefficients between education and PA/NA differed significantly between the groups of employed and unemployed people. A stronger association between education and PA/NA in unemployed than in employed people would suggest that education serves as human capital or a resource during unemployment ${ }^{2}$. Table 4 shows the results of the regression analyses in the group of unemployed people, and Table 5 the results for employed persons. As in the previous analyses, the model fit indices showed acceptable values for the multigroup analyses.

Contrary to our expectations, Model 1 (low vs. high education) revealed no significant associations between education and PA/NA in either group. Likewise, Model 2 (low vs. moderate education) and Model 3 (moderate vs. high education) did not show any significant associations between education and the facets of PA and NA in either group. All in 


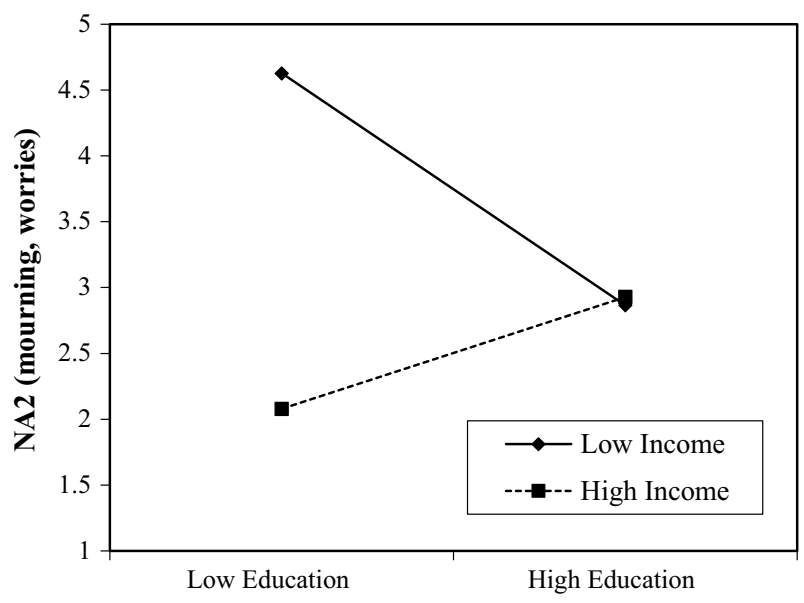

Fig. 2 Interaction of education and personal income for low versus high educated people

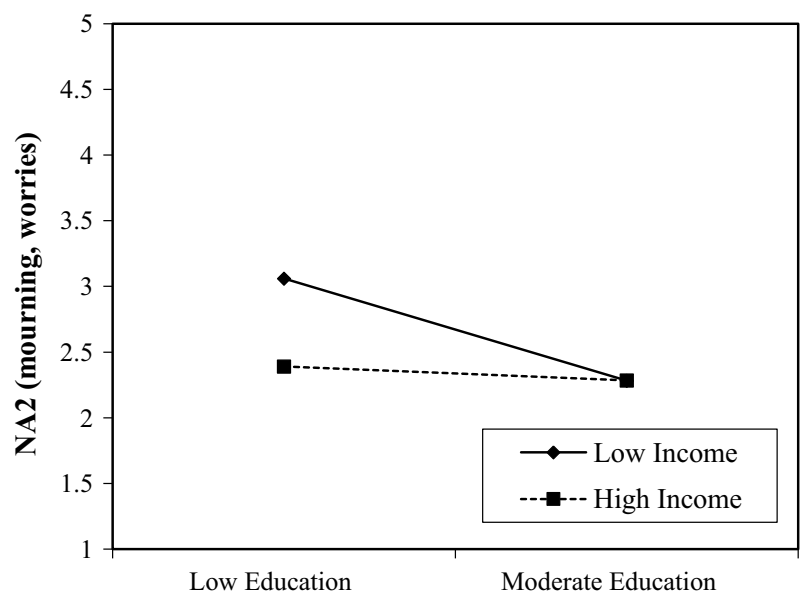

Fig. 3 Interaction of education and personal income for low versus moderately educated people

all, we did not find evidence for the notion that education might function as human capital during unemployment.

\subsubsection{Retirement}

To identify a possible interaction between education and retirement with regard to PA and the different NA factors, we used the same procedure as for employment status. That is, we analyzed whether the regression coefficients between education and PA/NA differed significantly between the groups of retired and non-retired people. Again, we demonstrated partial measurement invariance across both groups for PA and NA. Table 6 shows the results 
Table 4 Standardized regression coefficients for educational attainment and PA/NA for unemployed people

\begin{tabular}{|c|c|c|c|c|}
\hline $\begin{array}{l}\text { Affect factors-between- } \\
\text { level- }\end{array}$ & PA & $\begin{array}{l}\text { NA1 (Anger, } \\
\text { Frustration, } \\
\text { Stress) }\end{array}$ & $\begin{array}{l}\text { NA2 (Mourning, Wor- } \\
\text { ries) }\end{array}$ & $\begin{array}{l}\text { NA3 (Loneli- } \\
\text { ness, Boredom) }\end{array}$ \\
\hline
\end{tabular}

\begin{tabular}{|c|c|c|c|c|}
\hline \multicolumn{5}{|l|}{ Model $1^{\mathrm{a}}$} \\
\hline ISCED (low vs. high) & $-0.062(0.12)$ & $-0.022(0.11)$ & $-0.101(0.11)$ & $-0.079(0.11)$ \\
\hline Gender & $0.036(0.13)$ & $0.044(0.13)$ & $-0.078(0.12)$ & $-0.118(0.12)$ \\
\hline Age & $-0.119(0.13)$ & $-0.326(0.09)^{*}$ & $-0.035(0.13)$ & $-0.030(0.14)$ \\
\hline \multicolumn{5}{|l|}{ Model $2^{\mathrm{b}}$} \\
\hline $\begin{array}{l}\text { ISCED (low vs. moder- } \\
\text { ate) }\end{array}$ & $-0.007(0.07)$ & $-0.090(0.09)$ & $-0.115(0.09)$ & $-0.089(0.08)$ \\
\hline Gender & $0.063(0.08)$ & $0.030(0.07)$ & $-0.046(0.08)$ & $-0.232(0.09)^{*}$ \\
\hline Age & $-0.277(0.08)^{*}$ & $-0.199(0.09)$ & $.009(0.07)$ & $0.006(0.08)$ \\
\hline \multicolumn{5}{|l|}{ Model $3^{\mathrm{c}}$} \\
\hline $\begin{array}{l}\text { ISCED (moderate vs. } \\
\text { high) }\end{array}$ & $-0.023(0.08)$ & $0.062(0.08)$ & $0.029(0.08)$ & $-0.018(0.08)$ \\
\hline Gender & $0.089(0.08)$ & $-0.047(0.09)$ & $-0.153(0.08)$ & $-0.249(0.08)^{*}$ \\
\hline Age & $-0.148(0.09)$ & $-0.213(0.09)$ & $0.069(0.07)$ & $0.113(0.07)$ \\
\hline
\end{tabular}

${ }^{\mathrm{a}} k=109, \quad n=467$, Model fit indices: $\mathrm{CFI}=0.942, \quad$ SRMR-within $=0.055$, SRMR-between $=0.077$, RMSEA $=0.040$

b $\mathrm{k}=226, n=1028$, Model fit indices: $\mathrm{CFI}=0.962$, SRMR-within $=0.034$, SRMR-between $=0.060$, RMSEA $=0.031$

${ }^{c} \mathrm{k}=241, n=1085$, Model fit indices: $\mathrm{CFI}=0.952$, SRMR-within $=0.036$, SRMR-between $=0.062$, RMSEA $=0.034$

Standard errors are shown in brackets. $* p<0.01$. Gender: $0=$ male, $1=$ female

of the regression analyses for the group of non-retired people, and Table 7 the results for retirees. The model fit indices exhibited acceptable values for this multigroup analysis.

In Model 1 (low vs. high education), education was negatively related to NA2 (mourning, worries) in the group of retired but not in the group of non-retired people. The $\chi^{2}-$ test statistics showed, however, that the regression coefficients between education and NA2 (mourning, worries) did not differ significantly between the groups $\left(\Delta \chi^{2}(1)=2.88\right.$, $p>0.05$ ). The relationship between education and NA3 (boredom, loneliness) was also negative in the group of retirees but not significant in the group of non-retired people. The $\chi^{2}$-test statistics, however, revealed that the regression coefficients between education and NA3 (boredom, loneliness) did not differ significantly between groups $\left(\Delta \chi^{2}(1)=0.81\right.$, $p>0.05$ ). Model 2 (low vs. moderate education) showed the same pattern of findings. The associations between education and NA2 (mourning, worries) as well as NA3 (boredom, loneliness) were only negative in the group of retirees. The $\chi^{2}$-test statistics showed that the regression coefficients for NA2 (mourning, worries) and NA3 (boredom, loneliness) did not differ significantly between retired and non-retired persons (for NA2: $\Delta \chi^{2}(1)=1.59$, $p>0.05$; for NA3: $\Delta \chi^{2}(1)=0.69, p>0.05$ ). In Model 3 (moderate vs. high education), there were no significant associations between education and PA/NA in both groups.

Although these results showed numerically different associations between education and the facets of affect in the two groups (NA2 (mourning, worries) and NA3 (boredom, loneliness)), the associations did not differ significantly. This indicates that there was no reliable interaction between retirement status and education regarding affective well-being. 
Table 5 Standardized regression coefficients for educational attainment and PA/NA for employed people

\begin{tabular}{|c|c|c|c|c|}
\hline $\begin{array}{l}\text { Affect factors-between- } \\
\text { level- }\end{array}$ & PA & $\begin{array}{l}\text { NA1 (Anger, } \\
\text { Frustration, } \\
\text { Stress) }\end{array}$ & NA2 (Mourning, Worries) & $\begin{array}{l}\text { NA3 (Loneli- } \\
\text { ness, Boredom) }\end{array}$ \\
\hline \multicolumn{5}{|l|}{ Model $1^{\mathrm{a}}$} \\
\hline ISCED (low vs. high) & $0.015(0.08)$ & $-0.038(0.08)$ & $-0.032(0.08)$ & $-0.211(0.10)$ \\
\hline Gender & $0.017(0.07)$ & $0.122(0.07)$ & $0.136(0.07)$ & $0.044(0.07)$ \\
\hline Age & $0.027(0.07)$ & $-0.164(0.08)$ & $-0.042(0.07)$ & $-0.138(0.08)$ \\
\hline \multicolumn{5}{|l|}{ Model $2^{\mathrm{b}}$} \\
\hline $\begin{array}{l}\text { ISCED (low vs. moder- } \\
\text { ate) }\end{array}$ & $-0.007(0.06)$ & $-0.070(0.06)$ & $-0.018(0.06)$ & $-0.136(0.07)$ \\
\hline Gender & $-0.027(0.06)$ & $-0.080(0.06)$ & $.007(0.05)$ & $-0.061(0.06)$ \\
\hline Age & $-0.090(0.06)$ & $-0.217(0.06)^{*}$ & $-0.058(0.06)$ & $-0.190(0.06)^{*}$ \\
\hline \multicolumn{5}{|l|}{ Model $3^{\mathrm{c}}$} \\
\hline $\begin{array}{l}\text { ISCED (moderate vs. } \\
\text { high) }\end{array}$ & $0.023(0.05)$ & $0.055(0.05)$ & $-0.015(0.05)$ & $-0.028(0.05)$ \\
\hline Gender & $-0.009(0.05)$ & $-0.009(0.05)$ & $0.048(0.05)$ & $-0.023(0.05)$ \\
\hline Age & $-0.073(0.05)$ & $-0.194(0.05)^{*}$ & $-0.029(0.05)$ & $-0.190(0.05)^{*}$ \\
\hline
\end{tabular}

${ }^{\mathrm{a}} k=339, n=1668$, Model fit indices: CFI $=0.942$, SRMR-within $=0.055$, SRMR-between $=0.077$, RMSEA $=0.040$

b $k=429, n=2385$, Model fit indices: $\mathrm{CFI}=0.962$, SRMR-Within $=0.034$, SRMR-between $=0.060$, RMSEA $=0.031$

c $k=737, n=3585$, Model fit indices: $\mathrm{CFI}=0.952$, SRMR-Within $=.036$, SRMR-between $=0.052$, RMSEA $=0.034$

Standard errors are shown in brackets.* $p<0.01$. Gender: $0=$ male, $1=$ female

\section{Discussion}

This study examined the relationship between education and the affective component of subjective well-being (i.e., PA and NA) with a particular focus on specific sub-facets of NA in everyday life. Furthermore, we investigated how income, unemployment, and retirement affect the relationship between education and affective well-being. The main finding was that higher educated persons reported less boredom/loneliness and mourning/worries in everyday life than their less educated counterparts. Moreover, we found effects of income linking education and affective well-being for NA2 (mourning, worries). Additionally, we found an interaction effect between education and income for mourning/worries, according to which lower educated persons reported more mourning and worries than higher educated persons only when they had comparatively low incomes. Finally, this study did not provide evidence that education functions as human capital during unemployment and retirement. 
Table 6 Standardized regression coefficients for educational attainment and PA/NA for non-retired people

\begin{tabular}{lrlrl}
\hline $\begin{array}{l}\text { Affect factors-between- } \\
\text { level- }\end{array}$ & PA & $\begin{array}{l}\text { NA1 (Anger, } \\
\text { Frustration, } \\
\text { Stress) }\end{array}$ & NA2 (Mourning, Worries) & $\begin{array}{l}\text { NA3 } \\
\text { (Loneliness, } \\
\text { Boredom) }\end{array}$ \\
\hline $\begin{array}{l}\text { Model 1 } \\
\text { a }\end{array}$ & $-0.024(0.06)$ & $-0.045(0.07)$ & $-0.098(0.07)$ & $-0.175(0.07)$ \\
ISCED (low vs. high) & $0.013(0.06)$ & $0.098(0.06)$ & $0.101(0.06)$ & $0.022(0.06)$ \\
Gender & $-0.019(0.07)$ & $-0.196(0.07)^{*}$ & $-0.023(0.08)$ & $-0.087(0.08)$ \\
Age & $-0.020(0.05)$ & $-0.087(0.05)$ & $-0.072(0.05)$ & $-0.115(0.05)$ \\
Model 2 & & & & $-0.104(0.05)$ \\
ISCED (low vs. moder- \\
$\quad$ ate)
\end{tabular}

a $k=432, n=2087$, Model fit indices: CFI $=0.943$, SRMR-Within $=0.049$, SRMR-Between $=0.063$, RMSEA $=0.038$

b $k=690, n=3329$, Model fit indices: CFI $=0.956$, SRMR-Within $=0.042$, SRMR-Between $=0.050$, RMSEA $=0.032$

c $k=942, n=4562$, Model fit indices: CFI $=0.953$, SRMR-Within $=0.044$, SRMR-Between $=0.052$, RMSEA $=0.033$

The results remain robust, even if only people older than 40 years are included in the group of employed people

Standard errors are shown in brackets. $* x<0.01$. Gender: $0=$ male, $1=$ female

\subsection{Education and Affective Well-being}

One of the important findings of this study is that higher educated persons experience less NA than lower educated persons in everyday life, specifically regarding the sub-facets mourning/worries and loneliness/boredom. There are several potential reasons for this finding. First, higher education is related to better health behaviors, such as less smoking or more physical exercise (Ross and Wu 1995). Better health, in turn, is associated with a higher level of SWB (Diener 1984). A second possible explanation is given by Cummins (2000) whose model postulates that three psychological variables mediate the link between education and well-being: control, self-esteem, and optimism. According to this model, education fosters control of one's own environment, a higher level of self-esteem, and a positive perspective on the future. These three factors, in turn, affect well-being positively and could be potential mechanisms linking education and well-being. A third reason could be that higher educated people have better functioning social networks, which directly reduces or makes it easier to deal with negative emotions, such as mourning or loneliness, in everyday life due to better social support. For example, Chen (2012) reported that social networks were important mediators between education and SWB in an East Asian sample. Thus, better interpersonal relationships and better social support seem to have buffering effects on negative emotions. 
Table 7 Standardized regression coefficients for educational attainment and PA/NA for retired people

\begin{tabular}{|c|c|c|c|c|}
\hline $\begin{array}{l}\text { Affect factors-between- } \\
\text { level- }\end{array}$ & PA & $\begin{array}{l}\text { NA1 (Anger, } \\
\text { Frustration, } \\
\text { Stress) }\end{array}$ & NA2 (Mourning, Worries) & $\begin{array}{l}\text { NA3 (Loneli- } \\
\text { ness, Boredom) }\end{array}$ \\
\hline
\end{tabular}

\begin{tabular}{|c|c|c|c|c|}
\hline \multicolumn{5}{|l|}{ Model $1^{\mathrm{a}}$} \\
\hline ISCED (low vs. high) & $-0.035(0.09)$ & $-0.152(0.09)$ & $-0.288(0.08)^{*}$ & $-0.219(0.07)^{*}$ \\
\hline Gender & $-0.038(0.08)$ & $0.074(0.09)$ & $0.003(0.07)$ & $0.037(0.08)$ \\
\hline Age & $-0.040(0.07)$ & $-0.116(0.10)$ & $-0.027(0.10)$ & $0.102(0.06)$ \\
\hline \multicolumn{5}{|l|}{ Model $2^{b}$} \\
\hline $\begin{array}{l}\text { ISCED (low vs. moder- } \\
\text { ate) }\end{array}$ & $-0.094(0.05)$ & $-0.098(0.06)$ & $-0.203(0.06)^{*}$ & $-0.168(0.06)^{*}$ \\
\hline Gender & $-0.022(0.06)$ & $-0.013(0.06)$ & $0.016(0.05)$ & $-0.025(0.05)$ \\
\hline Age & $-0.116(0.05)$ & $-0.007(0.07)$ & $0.037(0.06)$ & $0.115(0.06)$ \\
\hline \multicolumn{5}{|l|}{ Model $3^{c}$} \\
\hline $\begin{array}{l}\text { ISCED (moderate vs. } \\
\text { high) }\end{array}$ & $0.055(0.05)$ & $-0.054(0.05)$ & $-0.054(0.05)$ & $-0.066(0.05)$ \\
\hline Gender & $-0.026(0.05)$ & $0.001(0.06)$ & $-0.024(0.05)$ & $-0.040(0.05)$ \\
\hline Age & $-0.120(0.05)$ & $0.016(0.07)$ & $0108(0.05)^{*}$ & $0.099(0.06)$ \\
\hline
\end{tabular}

${ }^{\mathrm{a}} k=246, n=1202$, Model fit indices: CFI $=0.943$, SRMR-Within $=0.049$, SRMR-Between $=0.063$, RMSEA $=0.038$

b $k=476, n=2341$, Model fit indices: CFI $=0.956$, SRMR-Within $=0.042$, SRMR-Between $=0.050$, RMSEA $=0.032$

c $k=506, n=2501$, Model fit indices: CFI $=0.953$, SRMR-Within $=0.044$, SRMR-Between $=0.052$, $\mathrm{RMSEA}=0.033$

Standard errors are shown in brackets. $* p<0.01$. Gender: $0=$ male, $1=$ female

In contrast to NA, education was not related to PA; this finding is possibly influenced by the way PA was measured in this study. Unfortunately, the SOEP-IS contains only three items to measure PA. Therefore, we could only model one latent factor for PA. This structure may not capture all sub-facets of PA (e.g., low-arousal sub-facets such as the state of being calm or relaxed), some of which might have a relation to education. However, a nonsignificant (Kahneman and Deaton 2010) or even a negative association between education and PA (Miret et al. 2014) was reported by a previous study. Therefore, further studies should also measure multiple facets of PA to gain more information about the association between education and PA.

While the generally negative relationship between education and NA is consistent with previous literature, our study provided some insights into this relationship. First, our approach of modeling three latent NA factors instead of using aggregated composite scores is in line with appraisal theories which postulate phenomenologically more nuanced affective states (e.g., Lazarus 1991; Scherer 2001). Our factors represent different sub-facets of NA. NA1 (anger, frustration, stress) is characterized by a high level of arousal. In contrast, NA2 (mourning, worries) and NA3 (boredom, loneliness) represent moderate to low levels of arousal and reflect specific feelings that are high in valence. The results showed that there are significant negative associations between education and NA2 (mourning, worries) as well as NA3 (boredom, loneliness). Education thus particularly seems to influence facets of negative affect that are characterized by a high negative valence, such as mourning or loneliness (NA2 and NA3). In contrast, facets of affect that are characterized by high 
arousal, such as anger, seem to be less related to education. A possible explanation for this finding could be that more specific negative emotions such as mourning or loneliness can be better handled by higher educated persons because their social networks function better, but that the higher educated cannot handle NA facets such as anger better. Another explanation for the non-significant association between education and NA1 (anger, frustration, stress) could be confounding effects of age. Interestingly, the correlation between education and NA1 was positive for Model 1 ("low vs. high education") and Model 3 ("moderate vs. high education"), but the standardized regression coefficients were not significant. Note that education correlated negatively with age, and age correlated negatively with NA1. Therefore, it is possible that older people tend to have a lower education but they also experience less anger, frustration, and stress in their everyday lives than younger people. Thus, the association between education and NA1 might be confounded by age.

Second, our results imply that the relationship between education and NA depends on the levels of education which are compared. We used the ISCED as a measure of education (Unesco 1997) and computed three dummy-coded variables to compare different levels of education (low vs. high education, low vs. moderate education, moderate vs. high education). This corresponds to a broad assessment of education and goes beyond school-leaving qualifications and also considers vocational training or a university degree. We found significant negative associations between education and NA only when comparing a low level of education with a moderate or high level of education. This apparent nonlinear relation and the question of whether it is particularly important to achieve a moderate level of education (upper secondary education/post-secondary non-tertiary education) in order to ensure an adequate level of affective well-being are important topics for further research. Fewer financial resources, precarious employment, and small social networks are possible reasons why particularly lower educated persons struggle with a high amount of negative emotions in everyday life.

\subsubsection{Income}

Income was examined as one monetary aspect that might affect the association between education and well-being. Our findings show that income might indeed be a potential pathway by which education affects affective well-being. The indirect effect of education via income on NA2 (mourning, worries) could be interpreted such that a higher education leads to a higher income which, in turn, may counteract financial worries. Importantly, this indirect effect was only found for NA2 (mourning and worries) and not for the other facets of affect, highlighting the importance of modeling the sub-facets of NA. In general, it must be noted that no conclusions can be drawn about causal relationships between education, income, and affective well-being due to the correlative study design. Thus, it is possible that more affluent people can achieve a higher level of education, which may lead to better affective well-being in everyday life.

In addition to the indirect effects of education via personal income, income also moderated the effect of education on NA2 (mourning, worries). While the relationship between education and NA2 was negative for lower incomes (lower educated persons reported more mourning and worries), the differences in NA2 between lower educated and higher educated persons were smaller for higher incomes. In other words, income can be interpreted as having a buffering effect for lower educated people, as higher personal income is associated with less mourning and worries. In contrast, income has no effect on mourning and worries in everyday life for higher educated people. 
To sum up, the role of income in the education-well-being relationship appears quite specific in this study; income seems to make a difference particularly for those who are less educated. Education remains an important covariate for negative emotions in our study, regardless of personal income. For this reason, the notion that income is the main mechanism between education and SWB seems unlikely (Clark et al., 2008), and thus, the nonmonetary effects of education play an important role.

\subsubsection{Employment Status}

Contrary to our expectations, we did not find an interaction between education and employment status regarding PA and NA. One explanation for not finding an effect might be that we did not consider the duration of unemployment. Studies have shown that the longer unemployment lasts, the more well-being decreases (McKee-Ryan et al. 2005). Moreover, long-term unemployment has been shown to be related with poorer health (Böckerman and Ilmakunnas 2009) and permanent psychological distress (Daly and Delaney 2013). Since our study has a cross-sectional design, we could not investigate the dynamic processes of well-being during unemployment.

Another potential explanation could be that higher educated people have higher aspirations, counteracting the potential buffering effect of education in periods of unemployment. They may experience a greater drop in income and prestige when entering unemployment than their less educated counterparts which, in turn, could lead to them to experience more negative emotions than less educated persons. For example, Clark and Oswald (1996) found that higher educated people showed a lower level of well-being in Britain in the 1990s and suggested that this was due to a particularly sharp drop in income following the economic recession.

Finally, based on our findings, we cannot draw conclusions on whether there are differences in affective well-being between employed and unemployed individuals. For example, a German DRM study showed, that while there were differences in life satisfaction between employed and unemployed, there were no differences in affective well-being (Knabe et al. 2010). In the study, the authors argued that unemployed individuals feel generally sadder than people in employment, but they can compensate this by pursuing more enjoyable activities during times when employed individuals need to work.

\subsubsection{Retirement}

Finally, we investigated the interaction between education and retirement status. Surprisingly, we could not find a significant interaction between education and retirement. Similar to unemployment, higher and lower educated persons might adapt their aspirations differently upon retirement and this may play a role. Higher educated persons may be more likely to have had jobs that were important and meaningful for them than less educated persons. Therefore, the absence of such meaningful work-related activities may counteract other, potentially positive, effects of education on retirement (e.g., larger social networks that facilitate retirement).

Another reason could be that retirement can also have a positive effect on affective wellbeing depending on the situation before retirement. For example, Hetschko et al. (2014) showed that retirement has a positive effect on life satisfaction when people were previously unemployed. 


\section{Limitations and Conclusion}

This study also has some noteworthy limitations. First, we could only investigate correlative associations and could not make any causal assertions about the relationship between education and affective well-being. For this purpose, different methodological approaches, including quasi-experimental and longitudinal research designs, are necessary. Second, it would be of interest to consider a broader scope of PA with more items and latent sub-facets to ensure a more differentiated measurement of PA than we did here. In particular, it would be relevant to examine the extent to which education is related to facets of PA that are characterized by low arousal, such as the states of being relaxed or calm, which could not be considered in this study. Such facets of PA are likely to occur more frequently in everyday life than "enthusiasm" and may thus have greater relevance for education as a covariate. Third, only three randomly selected episodes per day were rated regarding PA and NA. However, various scholars have demonstrated the validity and reliability of this random-sampling approach (Anusic et al. 2017; Hudson et al. 2017; Möwisch et al. 2019). Fourth, although the DRM is less timeintensive than other repeated-measurement designs such as the Experience Sampling Method (ESM), DRM measurements may be more biased by expectations related to how people normally feel in specific situations (Lucas et al. 2019). Nevertheless, the DRM provides comparable results to the ESM when examining between-person differences (Dockray et al. 2010; Lucas et al. 2019). Fifth, the significant effects of education on NA2 and NA3 were potentially mainly driven by retired persons because the regression coefficients were only significant in the retired subsample. Note, however, that the subsamples with non-significant effects of education on NA2 and NA3 were smaller than the retired subsample, and the lack of significant effects might simply be due to a lack of statistical power.

To sum up, this study provides new insights into the relationship between education and well-being by investigating specifically the affective component of SWB (PA and NA) with a focus on several sub-facets (e.g., stress-related states vs. sadness-related states). One implication of this study is that the comprehensive measurement and modeling of affective experiences can reveal differential outcome patterns that would be overlooked when working with a global composite score of NA. Other implications emerge from the nonlinear relationship between education and affective well-being: According to this study, especially people with low educational backgrounds have to deal with negative emotions such as worries, boredom, or loneliness in everyday life. Finally, we showed an association between education and affective well-being beyond income. Further research should therefore also explore other non-monetary mechanisms linking education and affective well-being.

\section{Funding Open Access funding provided by Projekt DEAL.}

Open Access This article is licensed under a Creative Commons Attribution 4.0 International License, which permits use, sharing, adaptation, distribution and reproduction in any medium or format, as long as you give appropriate credit to the original author(s) and the source, provide a link to the Creative Commons licence, and indicate if changes were made. The images or other third party material in this article are included in the article's Creative Commons licence, unless indicated otherwise in a credit line to the material. If material is not included in the article's Creative Commons licence and your intended use is not permitted by statutory regulation or exceeds the permitted use, you will need to obtain permission directly from the copyright holder. To view a copy of this licence, visit http://creativecommons.org/licenses/by/4.0/. 


\section{References}

Anand, P., Hunter, G., \& Smith, R. (2005). Capabilities and well-being: Evidence based on the Sen-Nussbaum approach to welfare. Social Indicators Research, 74(1), 9-55. https://doi.org/10.1007/s1120 5-005-6518-z.

Anusic, I., Lucas, R. E., \& Donnellan, M. B. (2017). The validity of the day reconstruction method in the German socio-economic panel study. Social Indicators Research, 130(1), 213-232. https://doi. org/10.1007/s11205-015-1172-6.

Aryee, S., Luk, V., Leung, A., \& Lo, S. (1999). Role stressors, interrole conflict, and well-being: The moderating influence of spousal support and coping behaviors among employed parents in Hong Kong. Journal of Vocational Behavior, 54(2), 259-278. https://doi.org/10.1006/jvb.1998.1667.

Becker, G. S. (1993). Human capital: A theoretical and empirical analysis with special reference to education (3rd ed.). Chicago, IL: The University of Chicago Press.

Blanchflower, D. G., \& Oswald, A. J. (2004). Well-being over time in Britain and the USA. Journal of Public Economics, 88(7-8), 1359-1386. https://doi.org/10.1016/S0047-2727(02)00168-8.

Böckerman, P., \& Ilmakunnas, P. (2009). Unemployment and self-assessed health: Evidence from panel data. Health Economics, 18(2), 161-179. https://doi.org/10.1002/hec.1361.

Brown, T. A. (2014). Confirmatory factor analysis for applied research. New York, NY: Guilford Publications.

Chen, W. (2012). How education enhances happiness: Comparison of mediating factors in four East Asian countries. Social Indicators Research, 106(1), 117-131. https://doi.org/10.1007/s1120 5-011-9798-5.

Clark, A. E., Frijters, P., \& Shields, M. A. (2008). Relative income, happiness, and utility: An explanation for the Easterlin paradox and other puzzles. Journal of Economic Literature, 46(1), 95-144. https://doi.org/10.1257/jel.46.1.95.

Clark, A. E., \& Oswald, A. J. (1996). Satisfaction and comparison income. Journal of Public Economics, 61(3), 359-381. https://doi.org/10.1016/0047-2727(95)01564-7.

Collins, A. L., Sarkisian, N., \& Winner, E. (2009). Flow and happiness in later life: An investigation into the role of daily and weekly flow experiences. Journal of Happiness Studies, 10(6), 703-719. https ://doi.org/10.1007/s10902-008-9116-3.

Conner, T. S., \& Barrett, L. F. (2012). Trends in ambulatory self-report: The role of momentary experience in psychosomatic medicine. Psychosomatic Medicine, 74(4), 327-337. https://doi. org/10.1097/PSY.0b013e3182546f18.

Crawford, J. R., \& Henry, J. D. (2004). The Positive and Negative Affect Schedule (PANAS): Construct validity, measurement properties and normative data in a large non-clinical sample. British Journal of Clinical Psychology, 43(3), 245-265. https://doi.org/10.1348/0144665031752934.

Crisp, D. A., Windsor, T. D., Butterworth, P., \& Anstey, K. J. (2015). Adapting to retirement community life: Changes in social networks and perceived loneliness. Journal of Relationships Research, 6, e9. https://doi.org/10.1017/jrr.2015.5.

Cummins, R. A. (2000). Personal income and subjective well-being: A review. Journal of Happiness Studies, 1(2), 133-158. https://doi.org/10.1023/A:1010079728426.

Cuñado, J., \& de Gracia, F. P. (2012). Does education affect happiness? Evidence for Spain. Social Indicators Research, 108(1), 185-196. https://doi.org/10.1007/s11205-011-9874-x.

Daly, M., \& Delaney, L. (2013). The scarring effect of unemployment throughout adulthood on psychological distress at age 50: Estimates controlling for early adulthood distress and childhood psychological factors. Social Science \& Medicine, 80, 19-23. https://doi.org/10.1016/j.socscimed.2012.12.008.

Desjardins, R. (2008). Researching the links between education and well-being. European Journal of Education, 43(1), 23-35. https://doi.org/10.1111/j.1465-3435.2007.00333.x.

Diener, E. (1984). Subjective well-being. Psychological Bulletin, 95(3), 542-575. https://doi. org/10.1037/0033-2909.95.3.542.

Diener, E., \& Scollon, C. N. (2014). The what, why, when, and how of teaching the science of subjective well-being. Teaching of Psychology, 41(2), 175-183. https://doi.org/10.1177/0098628314530346.

Diener, E., Suh, E. M., Lucas, R. E., \& Smith, H. L. (1999). Subjective well-being: Three decades of progress. Psychological Bulletin, 125(2), 276-302. https://doi.org/10.1037/0033-2909.125.2.276.

Dockray, S., Grant, N., Stone, A. A., Kahneman, D., Wardle, J., \& Steptoe, A. (2010). A comparison of affect ratings obtained with ecological momentary assessment and the Day Reconstruction Method. Social Indicators Research, 99, 269-283. https://doi.org/10.1007/s11205-010-9578-7.

Dolan, P., Peasgood, T., \& White, M. (2008). Do we really know what makes us happy? A review of the economic literature on the factors associated with subjective well-being. Journal of Economic Psychology, 29(1), 94-122. https://doi.org/10.1016/j.joep.2007.09.001. 
Easterbrook, M. J., Kuppens, T., \& Manstead, A. S. (2016). The education effect: Higher educational qualifications are robustly associated with beneficial personal and socio-political outcomes. Social Indicators Research, 126(3), 1261-1298. https://doi.org/10.1007/s11205-015-0946-1.

Ferrer-i-Carbonell, A. (2005). Income and well-being: an empirical analysis of the comparison income effect. Journal of Public Economics, 89(5-6), 997-1019. https://doi.org/10.1016/j.jpube co.2004.06.003.

Gardner, J., \& Oswald, A. J. (2007). Money and mental wellbeing: A longitudinal study of mediumsized lottery wins. Journal of Health Economics, 26(1), 49-60. https://doi.org/10.1016/j.jheal eco.2006.08.004.

Headey, B. (2008). Life goals matter to happiness: A revision of set-point theory. Social Indicators Research, 86(2), 213-231. https://doi.org/10.1007/s11205-007-9138-y.

Helliwell, J. F., Layard, R., \& Sachs, J. (2012). World Happiness Report. New York, NY: The Earth Institute, Columbia University. Retrieved from https://s3.amazonaws.com/happiness-report/2012/World_Happi ness_Report_2012.pdf

Hetschko, C., Knabe, A., \& Schöb, R. (2014). Changing identity: Retiring from unemployment. The Economic Journal, 124(575), 149-166. https://doi.org/10.1111/ecoj.12046.

Howell, R. T., \& Howell, C. J. (2008). The relation of economic status to subjective well-being in developing countries: A meta-analysis. Psychological Bulletin, 134(4), 536-560. https://doi. org/10.1037/0033-2909.134.4.536.

Hu, L.-T., \& Bentler, P. M. (1999). Cutoff criteria for fit indexes in covariance structure analysis: Conventional criteria versus new alternatives. Structural Equation Modeling, 6(1), 1-55. https://doi.org/10.1080/10705 519909540118.

Hudson, N. W., Lucas, R. E., \& Donnellan, M. B. (2017). Day-to-day affect is surprisingly stable: A two-year longitudinal study of well-being. Social Psychological and Personality Science, 8(1), 45-54. https://doi. org/10.1177/1948550616662129.

Jongbloed, J. (2018). Higher education for happiness? Investigating the impact of education on the hedonic and eudaimonic well-being of Europeans. European Educational Research Journal, 17(5), 733-754. https:// doi.org/10.1177/1474904118770818.

Kahneman, D., \& Deaton, A. (2010). High income improves evaluation of life but not emotional well-being. Proceedings of the National Academy of Sciences of the United States of America, 107(38), 16489-16493. https://doi.org/10.1073/pnas.1011492107.

Kahneman, D., Krueger, A. B., Schkade, D. A., Schwarz, N., \& Stone, A. A. (2004a). Toward national wellbeing accounts. The American Economic Review, 94(2), 429-434. https://doi.org/10.1257/0002828041 301713.

Kahneman, D., Krueger, A. B., Schkade, D. A., Schwarz, N., \& Stone, A. A. (2004b). A survey method for characterizing daily life experience: The day reconstruction method. Science, 306(5702), 1776-1780. https ://doi.org/10.1126/science.1103572.

Kansky, J., \& Diener, E. (2017). Benefits of well-being: Health, social relationships, work, and resilience. Journal of Positive Psychology and Wellbeing, 1(2), 129-169.

Kim, J. E., \& Moen, P. (2002). Retirement transitions, gender, and psychological well-being: A life-course, ecological model. The Journals of Gerontology Series B: Psychological Sciences and Social Sciences, 57(3), 212-222. https://doi.org/10.1093/geronb/57.3.P212.

Knabe, A., Rätzel, S., Schöb, R., \& Weimann, J. (2010). Dissatisfied with life but having a good day: Timeuse and well-being of the unemployed. The Economic Journal, 120(547), 867-889. https://doi.org/10.111 1/j.1468-0297.2009.02347.x.

Lazarus, R. S. (1991). Emotion and adaptation. New York, NY: Oxford University Press.

Luhmann, M., Hofmann, W., Eid, M., \& Lucas, R. E. (2012). Subjective well-being and adaptation to life events: A meta-analysis. Journal of Personality and Social Psychology, 102(3), 592-615. https://doi. org/10.1037/a0025948.

Luhmann, M., Schimmack, U., \& Eid, M. (2011). Stability and variability in the relationship between subjective well-being and income. Journal of Research in Personality, 45(2), 186-197. https://doi.org/10.1016/j. jrp.2011.01.004.

Lucas, R. E., Wallsworth, C., Anusic, I., \& Donnellan, B. (2019). A direct comparison of the day reconstruction method and the experience sampling method.. https://doi.org/10.31234/osf.io/cv73u.

McKee-Ryan, F., Song, Z., Wanberg, C. R., \& Kinicki, A. J. (2005). Psychological and physical well-being during unemployment: A meta-analytic study. Journal of Applied Psychology, 90(1), 53-76. https://doi. org/10.1037/0021-9010.90.1.53.

McKee-Ryan, F. M., \& Kinicki, A. J. (2002). Coping with job loss: A life-facet perspective. In Cooper, C. L. \& Robertson, I. T. (Eds.), International Review of Industrial and Organizational Psychology, 2002, Volume 
17 (pp. 1-29). Chichester, England: John Wiley and Sons Ltd. https://doi.org/10.1002/9780470696392. ch1

Miret, M., Caballero, F. F., Chatterji, S., Olaya, B., Tobiasz-Adamczyk, B., Koskinen, S., et al. (2014). Health and happiness: cross-sectional household surveys in Finland, Poland and Spain. Bulletin of the World Health Organization, 92(10), 716-725. https://doi.org/10.2471/BLT.13.129254.

Moskowitz, J. T., Epel, E. S., \& Acree, M. (2008). Positive affect uniquely predicts lower risk of mortality in people with diabetes. Health Psychology, 27(1), 73-82. https://doi.org/10.1037/0278-6133.27.1.S73.

Möwisch, D., Schmiedek, F., Richter, D., \& Brose, A. (2019). Capturing affective well-being in daily life with the day reconstruction method: A refined view on positive and negative affect. Journal of Happiness Studies, 20(2), 641-663. https://doi.org/10.1007/s10902-018-9965-3.

Muthén, L. K., \& Muthén, B. O. (1998-2015). Mplus User's Guide. Seventh Edition. Los Angelos, CA: Muthen \& Muthen.

Nieminen, T., Martelin, T., Koskinen, S., Simpura, J., Alanen, E., Härkänen, T., et al. (2008). Measurement and socio-demographic variation of social capital in a large population-based survey. Social Indicators Research, 85(3), 405-423. https://doi.org/10.1007/s11205-007-9102-x.

Nikolaev, B. (2018). Does higher education increase hedonic and eudaimonic happiness? Journal of Happiness Studies, 19(2), 483-504. https://doi.org/10.1007/s10902-016-9833-y.

OECD. (2007). Understanding the social outcomes of learning. Paris, France: OECD Publishing.

Payne, R., \& Hartley, J. (1987). A test of a model for explaining the affective experience of unemployed men. Journal of Occupational Psychology, 60(1), 31-47. https://doi.org/10.1111/j.2044-8325.1987.tb00239.x.

Pettit, J. W., Kline, J. P., Gencoz, T., Gencoz, F., \& Joiner, T. E. (2001). Are happy people healthier? The specific role of positive affect in predicting self-reported health symptoms. Journal of Research in Personality, 35(4), 521-536.

Pichler, F., \& Wallace, C. (2009). Social capital and social class in Europe: The role of social networks in social stratification. European Sociological Review, 25(3), 319-332. https://doi.org/10.1093/esr/jcn050.

Powdthavee, N., Lekfuangfu, W. N., \& Wooden, M. (2015). What's the good of education on our overall quality of life? A simultaneous equation model of education and life satisfaction for Australia. Journal of Behavioral and Experimental Economics, 54, 10-21. https://doi.org/10.1016/j.socec.2014.11.002.

Richter, D., \& Schupp, J. (2015). The SOEP innovation sample (SOEP IS). Schmollers Jahrbuch, 135(3), 389399. https://doi.org/10.3790/schm.135.3.389.

Rief, W., Glaesmer, H., Baehr, V., Broadbent, E., Brähler, E., \& Petrie, K. J. (2012). The relationship of modern health worries to depression, symptom reporting and quality of life in a general population survey. Journal of Psychosomatic Research, 72(4), 318-320. https://doi.org/10.1016/j.jpsychores.2011.11.017.

Robinson, M. D., \& Clore, G. L. (2002). Belief and feeling: Evidence for an accessibility model of emotional self-report. Psychological Bulletin, 128(6), 934-960. https://doi.org/10.1037/0033-2909.128.6.934.

Ross, C. E., \& Van Willigen, M. (1997). Education and the subjective quality of life. Journal of Health and Social Behavior, 38(3), 275-297. https://doi.org/10.2307/2955371.

Ross, C. E., \& Wu, C.-L. (1995). The links between education and health. American Sociological Review, 60(5), 719-745. https://doi.org/10.2307/2096319.

Satorra, A., \& Bentler, P. M. (2001). A scaled difference chi-square test statistic for moment structure analysis. Psychometrika, 66(4), 507-514. https://doi.org/10.1007/BF02296192.

Scherer, K. R. (2001). Appraisal considered as a process of multi-level sequential checking. In K. R. Scherer, A. Schorr, \& T. Johnstone (Eds.), Appraisal processes in emotion: Theory, Methods, Research (pp. 92-120). New York and Oxford: Oxford University Press.

Schimmack, U. (1999). Strukturmodelle der Stimmungen: Rückschau, Rundschau und Ausschau [Structural models of mood: Review, overview, and outlook]. Psychologische Rundschau, 50, 90-97. https://doi. org/10.1026/0033-3042.50.2.90.

Struk, A. A., Scholer, A. A., \& Danckert, J. (2016). A self-regulatory approach to understanding boredom proneness. Cognition and Emotion, 30(8), 1388-1401. https://doi.org/10.1080/02699931.2015.1064363.

Tellegen, A., Watson, D., \& Clark, L. A. (1999). On the dimensional and hierarchical structure of affect. Psychological Science, 10(4), 297-303. https://doi.org/10.1111/1467-9280.00157.

United Nations Educational, Scientific and Cultural Organization (UNESCO). (1997). International Standard Classification of Education ISCED 1997. Paris, France: United Nations Educational, Scientific and Cultural Organization.

Vila, L. E. (2001). The non-monetary benefits of education. European Journal of Education, 35(1), 21-32. https ://doi.org/10.1111/1467-3435.00003.

Vila, L. E. (2005). The outcomes of investment in education and people's well-being. European Journal of Education, 40(1), 3-11. https://doi.org/10.1111/j.1465-3435.2005.00206.x.

Watson, D., \& Tellegen, A. (1985). Toward a consensual structure of mood. Psychological Bulletin, 98(2), 219235. https://doi.org/10.1037/0033-2909.98.2.219. 
Wetzel, M., \& Huxhold, O. (2016). Are leisure activity and health interconnected after retirement: Educational differences. Advances in Life Course Research, 30, 43-52. https://doi.org/10.1016/j.alcr.2016.03.007.

Witter, R. A., Okun, M. A., Stock, W. A., \& Haring, M. J. (1984). Education and subjective well-being: A metaanalysis. Educational Evaluation and Policy Analysis, 6(2), 165-173. https://doi.org/10.2307/1163911.

Publisher's Note Springer Nature remains neutral with regard to jurisdictional claims in published maps and institutional affiliations.

\section{Affiliations}

\section{Dave Möwisch $^{1,3} \cdot$ Annette Brose $^{2} \cdot$ Florian Schmiedek $^{1}$}

1 DIPF I Leibniz Institute for Research and Information in Education, Rostocker Straße 6, 60323 Frankfurt am Main, Germany

2 Department of Psychology, Humboldt-Universität Zu Berlin, Rudower Chaussee 18, 12489 Berlin, Germany

3 Leibniz Institute for Educational Trajectories, Wilhelmsplatz 3, 96047 Bamberg, Germany 